\title{
Angiomixoma agressivo em paciente do sexo masculino acometendo cordão espermático: relato de caso e revisão da literatura
}

\author{
Aggressive angiomyxoma in male patient on the spermatic cord: case report and literature review
}

Alexandre Nakao Odashiro'; Luciana Nakao Odashiro'; Danilo Nakao Odashiro'; Maçanori Odashiro'; José Carlos Prates Campos²

\section{unitermos}

Angiomixoma agressivo

Cordão espermático

\section{resumo}

Os autores relatam um caso de angiomixoma agressivo em paciente do sexo masculino, no cordão espermático. Essa entidade é descrita predominantemente em mulheres adultas, acometendo as regiões perineal, genital e pélvica. Macroscopicamente observou-se massa lobulada, infiltrativa, de limites imprecisos, que microscopicamente era representada por estroma mixóide com células pequenas, fusiformes e/ou estreladas, uniformes, sem figuras de mitose evidentes. Chamou atenção a presença de vasos sangüíneos proeminentes, de variados tamanhos, alguns deles com paredes espessadas. $O$ perfil imuno-histoquímico mostrou positividade focal para desmina e actina de músculo liso (1A4) e negatividade para CD34 e CD68. Muitas neoplasias mixóides, tanto benignas quanto malignas, podem ser confundidas com o angiomixoma agressivo. O diagnóstico diferencial deve ser amplamente estudado, pois essa neoplasia tem caráter infiltrativo, alto índice de recorrência, embora não haja metástases relatadas até o presente momento.
The authors report an aggressive angiomyxoma on the spermatic cord in a male patient. This entity occurs predominantly in adult women, in the perineal, genital and pelvic areas. The gross aspect is usually a lobulated mass, with infiltrative borders. At light microscopy there's a uniform myxoid background with small, spindle and stellate cells, with no evidence of mitoses. Characteristically there are numerous blood vessels, of variable sizes, some of them with thickening of the media. The immunohistochemical profile shows focal immunoreactivity for desmin and smooth muscle actin (1A4), and no reaction for CD34 and CD68. Other myxoid benign and malignant tumors can be confused with aggressive angiomyxoma. The differential diagnosis is important because the latter is infiltrative, with a high recurrence rate, although there is no metastasis reported until this moment. key words Aggressive angiomyxoma Spermatic cord

\section{Introdução}

Angiomixoma agressivo (AA) é uma neoplasia incomum que ocorre quase exclusivamente em partes moles da região pélvica de mulheres. É um tumor infiltrativo e recorrente após sua excisão, porém não apresenta metástases. Poucos casos têm sido descritos na literatura em pacientes do sexo masculino. Descrevemos um caso localizado no cordão espermático em um paciente de 53 anos.

\section{Relato do caso}

Paciente masculino, 53 anos, com aumento na bolsa escrotal unilateral há um ano. A macroscopia evidenciou massa irregular no cordão espermático, medindo $3 \times$ $3 \times 2,2 \mathrm{~cm}$, com aparência gelatinosa, homogênea e bordos infiltrativos. Microscopicamente, observou-se neoplasia hipocelular, com células pequenas, fusiformes a estreladas, com núcleo apresentando cromatina regular, com citoplasma escasso e mal delimitado,

1. Médico patologista do Laboratório de Anatomia Patológica e Citopatologia (LAC), Campo Grande (MS).

2. Médico patologista do Laboratório de Patologia Cirúrgica e Citopatologia do Hospital e Maternidade São Lucas, Ribeirão Preto (SP).

Trabalho apresentado na forma de pôster no XXIV Congresso Brasileiro de Patologia, realizado em Florianópolis (SC) de 30 de abril a 4 de maio de 2003. 
estando dispersas em estroma extremamente mixóide com delicadas fibras colágenas de permeio (Figura 1). Figuras de mitoses e necrose não foram observadas. Mastócitos eram conspícuos. Chamavam atenção proeminentes vasos sangüíneos de diversos calibres (Figura 2), alguns com paredes espessadas e hialinização da camada média, além de linfócitos e plasmócitos ao seu redor. Observou-se ainda área de tecido adiposo e de partes moles adjacente infiltrados pelo estroma mixóide do tumor (Figuras 3 e 4). $\mathrm{O}$ exame imuno-histoquímico demonstrou positividade para desmina e actina de músculo liso (1A4), focalmente. Foi negativo para os marcadores CD34 e para CD68.

\section{Discussão}

AA é uma neoplasia relativamente incomum, descrita primeiramente por Steeper e Rosai, em 1983. Acomete partes moles da região pélvica, especialmente de mulheres. Clinicamente se caracteriza por crescimento lento,

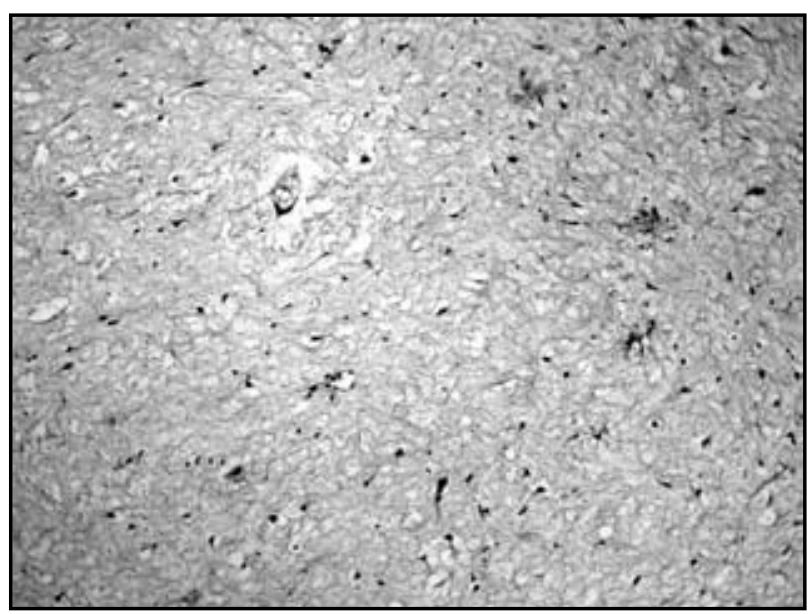

Figura 1 - Tumor hipocelular, com células de núcleos fusiformes em meio a estroma mixóide (HE 200x)

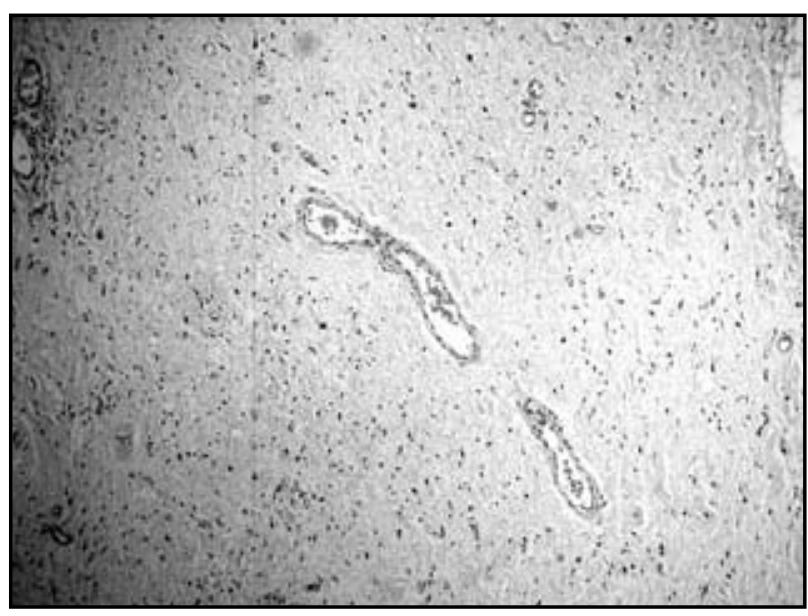

Figura 2 - Vasos sangüíneos em meio a estroma mixóide (HE 200x)

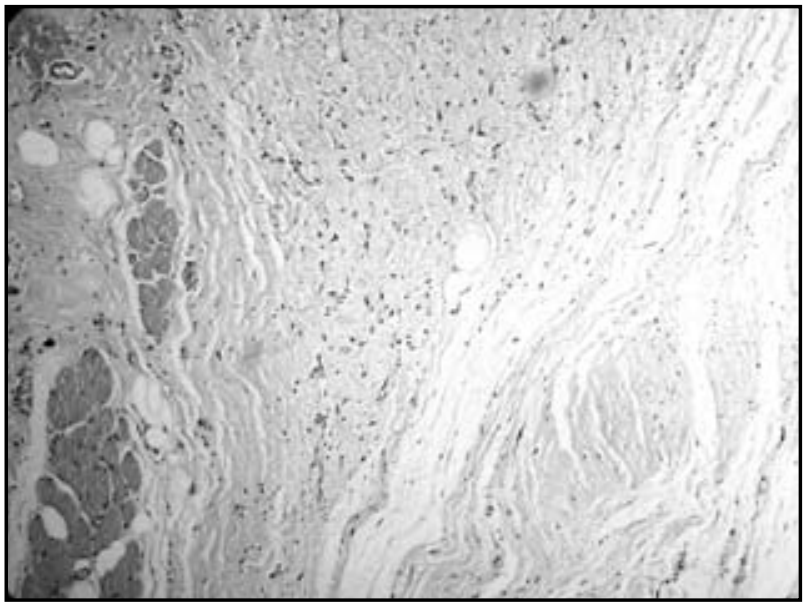

Figura 3 - Área de infiltração em partes moles adjacente a neoplasia (HE 200x)

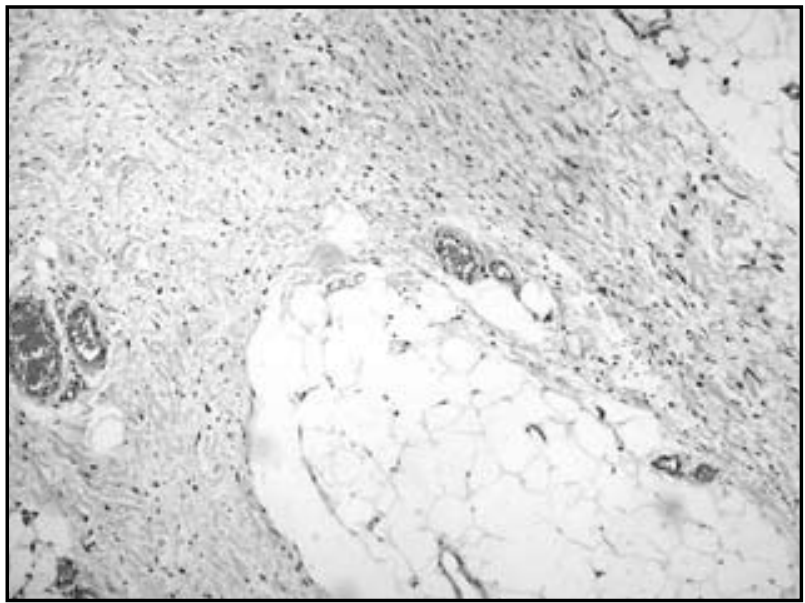

Figura 4 - Tecido adiposo aprisionado pelo tumor (HE 200x)

infiltrativo, e exibe recorrência local freqüente, porém não apresenta metástases ${ }^{(2,7,10,15,18)}$. Recorrência local pode estar relacionada a inadequada excisão do tumor devido ao seu caráter infiltrativo(2, 10,15, 18). A aparência desse tumor em exame de ressonância magnética é característica, e o diagnóstico deve ser considerado em qualquer mulher jovem apresentando uma massa bem definida no períneo ${ }^{(8)}$. Multifocalidade não é freqüente, mas foi descrita em alguns $\operatorname{casos}^{(9)}$.

Poucos casos de angiomixoma agressivo foram descritos em pacientes masculinos, com diferentes locais acometidos, como escroto ${ }^{(15)}$, períneo e região perianal(2), cordão espermático ${ }^{(16,18)}$, região inguinal(18) e partes moles da região pélvica ${ }^{(13,18)}$. As características clinicopatológicas desse tumor são similares em homens e mulheres ${ }^{(7)}$.

Histologicamente apresenta estroma mixóide, hipocelularidade, pequenas células mesenquimais fusiformes $\mathrm{e}$ estreladas, com citoplasma indistinto. Mitoses e pleomor- 
fismo celular nunca estão presentes. Caracteristicamente há um componente vascular proeminente com vasos de variados calibres, desde artérias e veias com camada média espessada até capilares/vênulas. Pequenos filetes nervosos e mastócitos são observados em meio ao estroma mixóide ${ }^{(1,}$ $2,7,13,15,16,18)$. Entretanto algumas variações dessa descrição clássica têm sido reportadas. Steeper sugere que em tumores recidivados podemos encontrar áreas mais celulares e menos mixóides ${ }^{(17)}$. Em raros casos as células estromais podem exibir multinucleação(2).

A imuno-histoquímica revela positividade para vimentina, sendo que a reação com desmina, actina de músculo específica e actina de músculo liso é variada $(2,3,6,7,15,16$, 18). CD34 foi positivo em alguns $\operatorname{casos}^{(3,16)}$ e negativo em outros $^{(3,7,11)}$. Alguns trabalhos sobre angiomixoma agressivo em mulheres mostraram positividade para receptores de estrógeno e/ou progesterona ${ }^{(3,13)}$. Fine et al. ${ }^{(4)}$ reportaram um caso no qual foi utilizado agonista $\mathrm{GnRH}$ em uma paciente com AA da vulva recorrente, positivo para esses receptores, com uma completa resolução do tumor à radiografia. Mas nenhum caso de AA em pacientes masculinos foi positivo para esses hormônios ${ }^{(13,16)}$.

No nível ultra-estrutural, as células tumorais do AA mostram diferenciação miofibroblástica ${ }^{(17)}$. Bégin et al. ${ }^{(2)}$ relataram que os achados à microscopia eletrônica eram sugestivos de diferenciação fibroblástica e não miofibroblástica. A nosso ver, a descrição no nível ultra-estrutural, somada aos achados imuno-histoquímicos, favorece a diferenciação miofibroblástica.

O diagnóstico diferencial do AA inclui neoplasias benignas e malignas ${ }^{(1)}$. Angiomixoma superficial, mixoma e neurofibroma mixóide podem ser confundidos, mas não apresentam os vasos calibrosos proeminentes, característicos do AA, além de apresentarem localizações habituais diferentes e, no caso do mixoma cutâneo e do neurofibroma mixóide, positividade imuno-histoquímica específica.

Tumores lipomatosos benignos e malignos com componente mesenquimal mixóide devem ser diferenciados, já que podem demonstrar tecido adiposo aprisionado na lesão(6).

$\mathrm{O}$ angiomixolipoma possui o tecido adiposo fazendo parte do tumor e não apresenta caráter infiltrativo ${ }^{(12)}$. $\mathrm{O}$ mixofibrossarcoma possui padrão vascular curvilinear, além de células atípicas e células bizarras lipoblastos-like contendo mucina.

O diagnóstico diferencial entre angiomiofibroblastoma e AA é muito citado na literatura ${ }^{(3,5,6,7,18)}$. O primeiro possui bordas circunscritas bem definidas, vascularização mais abundante com pequenos capilares, alternância de áreas de maior e menor celularidade e células fusiformes a ovais, além de estroma edemaciado mixóide. A imuno-histoquímica não ajuda a distinguir essas duas entidades ${ }^{(6,7)}$. As características ultra-estruturais mostram diferenciação miofibroblástica dessa neoplasia. Granter, Nucci e Fletcher descreveram 16 casos de AA em que três possuíam, histologicamente, áreas características do angiomiofibroblastoma, e concluíram que essas duas entidades estão altamente relacionadas em um espectro de tumores com origem miofibroblástica ${ }^{(6)}$.

Relatamos um caso de AA no cordão espermático, por ser incomum no sexo masculino e acreditarmos ser um diagnóstico que deve ser sempre lembrado, a fim de alertar o cirurgião sobre o alto índice de recorrência, sendo importante, portanto, uma excisão ampla do tumor.

\section{Referências}

I. ALLEN, P.W. Myxoid tumors of soft tissue. Pathol Annu, v. I5, p. |33-9|, 1980.

2. BÉGIN, L. R. et al. Aggressive angiomyxoma of pelvic soft parts: a clinicopathologic study of nine cases. Hum Pathol, v. 16 p. $621-8,1985$.

3. FETSCH, J. F. et al. Aggressive angiomyxoma: a clinicopathologic study of 29 female patients. Cancer, v. 78, p. 79-90, 1996.

4. FINE, B. A. et al. Primary medical management of recurrent aggressive angiomyxoma of the vulva with a gonadotropinreleasing hormone agonist. Gynecol Oncol, v. 81, p. I20-I, 2001.
5. FLETCHER, C. D. M. et al. Angiomyofibroblastoma of the vulva: a benign neoplasm distinct from aggressive angiomyxoma. Am J Surg Pathol, v. 16, p. 373-82, 1992.

6. GRANTER, S. R.; NUCCl, M. R.; FLETCHER, C. D. M. Aggressive angiomyxoma: reappraisal of its relationship to angiomyofibroblastoma in a series of 16 cases. Histopathology, v. 30, p. 3-10, 1997.

7. IEZZONI, J. C. et al. Aggressive angiomyxoma in males: a report of four cases. Am J Clin Pathol, v. I04, p. 391-6, 1995.

8. JEYADEVAN, N. N. et al. Imaging features of aggressive angiomyxoma. Clin Radiol, v. 58, p. 157-62, 2002. 
9. KAUR, A. et al. Multifocal aggressive angiomyxoma: a case report. J Clin Pathol, v. 53, p. 798-9, 2000.

10. LLANGER, J. et al. Aggressive angiomyxoma of pelvic soft tissue: CT appearance. Urol Radiol, v. 12, p. 25-6, 1990.

I I.MADRIGAL, B. et al.An aggressive inguinal (parafunicular) angiomyxoma in a male patient. Arch Esp Urol, v. 52, p. 785-8, 1999.

12. MAI, K.T. et al.Vascular myxolipoma (angiomyxolipoma) of the spermatic cord. Am J Surg Pathol, v. 20, p. I | 45-8, 1996.

13. McClugGAge, W. G.; PATTERSON, A.; MAXWELL, P. Aggressive angiomyxoma of pelvic parts exhibits oestrogen and progesterone receptor positivity. J Clin Pathol, v. 53, p. 603-5, 2000.

14. NUCCI, M. R.; FLETCHER, C. D. M.Vulvovaginal soft tissue tumors: update and review. Histopathology, v. 36, p. 97-108, 2000
15. ROJO, D. G. et al. Angiomixoma agresivo intraescrotal. Arch Esp Urol, v. 50, p. I I23-5, 1997.

16. SILVERMAN, J. S.; ALBUKERK, J.; TAMSEN, A. Comparison of angiomyofibroblastoma and aggressive angiomyxoma in both sexes: four cases composed of bimodal CD34 and factor XIlla positive dendritic cell subsets. Pathol Res Pract, v. 193, p. 673-82, 1997.

17.STEEPER,T.A.; ROSAI, J.Aggressive angiomyxoma of the female pelvis and perineum: report of nine cases of a distinctive type of gynecologic soft tissue neoplasm. Am J Surg Pathol, v. 7, p. 463-75, 1983

18. TSANG, W. Y.W. et al. Aggressive angiomyxoma: a report of four cases occurring in men. Am J Surg Pathol, v. I 6, p. 1059 65, 1992.
Endereço para correspondência

Alexandre Nakao Odashiro

LAC - Laboratório de Anatomia Patológica e

Citopatologia

R. Rui Barbosa 3.716

CEP 79002-362 - Campo Grande-MS

Fax: (67) 3027-7008

e-mail: alexandrenaka@@yahoo.com.br 